\title{
Accumulation of wear and tear in archival and library collections. Part I: exploring the concepts of reliability and epidemiology
}

\author{
Cristina Duran-Casablancas ${ }^{1,2^{*}}$, Josep Grau-Bové ${ }^{1}$ and Matija Strlič ${ }^{1}$
}

\begin{abstract}
Wear and tear is the outcome of degradation most frequently reported in assessments of archival and library collections. It is also problematic to study in controlled experiments, due to the difficulty in reproducing the conditions in which original objects are kept and used in archives and libraries. Hence, data collected from actual collections, for instance during surveys, could provide the evidence on how wear and tear occurs. However, to be useful, such data need to be purposely collected and analysed: unlike the usual collection surveys, the aim is not to quantify the prevalence of a certain damage type but to provide evidence on how such damage occurs. In this paper we explore whether two approaches used in other disciplines could be useful: reliability engineering, the method that deals with failure in complex systems, and epidemiology, which explores diseases in defined populations. We show that based on reliability engineering we can decide which data related to the causes of mechanical failure should be collected during collection surveys, while using epidemiology we can develop the study design and the data analysis needed to study the relationship between mechanical failure, and the factors that might affect the degree of failure. The results of epidemiological studies in heritage collections could provide quantitative evidence of patterns of decay in collections, and corroborate the qualitative analysis provided by reliability. The results can directly support collection management decisions or can be used in mathematical models in which the effect of preservation measures is explored.
\end{abstract}

Keywords: Wear and tear, Mechanical degradation, Archival and library collections, Survey, Reliability, Epidemiology

\section{Introduction}

During condition assessments in archives and libraries, mechanical degradation, understood as wear and tear, has repeatedly been identified as one of the most frequent types of damage [1, 2], associated with one of the highest risks for physical collections [3]. Within collections, mechanical degradation occurs almost unnoticed, starting with small tears along the edges, until parts become clearly missing. Since the rate of this process can be low, it is difficult to quantify. This was demonstrated in the risk assessment conducted at the National Archive

\footnotetext{
${ }^{*}$ Correspondence: cristina.casablancas.14@ucl.ac.uk;

c.duran@amsterdam.nl

${ }^{1}$ Institute for Sustainable Heritage, University College London, London, UK

Full list of author information is available at the end of the article
}

(UK). It was concluded that "[a]lthough the resulting loss of value and information to each document might be minute, the overall damage to the collection is considerable" [4].

Related to chemical degradation, a large body of research has led to the identification of the factors affecting the paper stability [5]. Endogenous factors (pH, lignin, metal ions etc.) and exogenous factors (heat, humidity, light etc.) have been distinguished. Remarkably, a comparable scheme of the factors involved in mechanical degradation has not been developed yet.

Surveys are an assessment tool used to extract information from the collections, usually regarding their preservation needs. During collection surveys, one option is to grade individual items according to the observed damage, such as tears or broken parts of bindings [6]. In such surveys the condition of an item is defined by the observed 
extent of damage. In other surveys, grading is based on the judgement whether handling would result in further damage [2]. Such surveys can therefore have a predictive character which is typical for risk assessments $[7,8]$. In contrast to surveys, the focus of risk assessments is not damage that has already occurred (assessed in surveys) but the potential for damage due to identified hazards [9].

The surveyor is charged with the complex task of grading a condition or a risk. In some surveys, this is based on additional experimental evidence, e.g. using the manual paper fold test [10-14] or chemical analyses (paper fibre identification, $\mathrm{pH}$, alum or lignin content). The surveyor thus estimates how the measured properties will affect the occurrence of (mechanical) degradation in the future. However, quantitative evidence to support these estimations has not been provided yet.

Besides the material's chemical properties, surveys can also collect environmental information [15-17]. Inappropriate storage conditions (from boxes to environmental control) are seen as a risk and the surveyor need to assess how the storage conditions will affect mechanical degradation. Surveys can also be extended to descriptive information about items [6,18-21]. This can include metadata (such as date and country of publication) and physical description of the objects, sometimes extensive: types of binding, cover materials, size etc. Information on whether the objects are in circulation can also be included.

Thus, surveys amass a large amount of data for different purposes and, consequently, they can be extremely timeconsuming. Remarkably, with a couple of exceptions [22, 23], which will be discussed later in this paper, the data is then mostly used to report the proportion of the collections showing signs of (mechanical) degradation at the point when the survey took place. For example, according to a survey conducted in 2013, 53\% of the collections in UK libraries and archives showed evidence of mechanical degradation [24]. Other examples report the prevalence of certain groups of objects to degradation. The Yale survey reported that limp bindings were more fragile than those with rigid covers [18]. And in the survey conducted at the Georgia State University's Pullen Library they observed that smaller, thicker books were in better condition than taller and thinner volumes [25].

The last two examples suggest that associations between wear and tear and different characteristics of the collections can be drawn from the survey data. But to provide robust evidence, specific experimental designs of the processes of data collection and analysis are needed.

In this paper we introduce some concepts used in reliability and epidemiology to find out how surveys could be modified to extract more quantitative evidence than just the prevalence of types of damage. We are specifically interested in how the mechanical degradation process in archival and library collections could be quantitatively described and studied.

Reliability engineering is a discipline which has developed a quantitative and formal approach to failure [26]. Reliability engineering has been applied in a broad number of areas [27], but only recently, the reliability engineering concept of the 'bathtub curve' has been introduced to explain the rate of wear and tear for paperbased material [28]. In the first part of this paper we explore the applicability of reliability concepts, such as failure rate and classification of failure causes, to evaluate the relevance of the information collected in surveys, and whether other factors should be included when studying the occurrence and accumulation of mechanical failure in the complex setting of the collections.

In the second part of this paper, we explore how epidemiology, a discipline developed to study diseases in (living) populations, could provide a quantitative approach to the study of mechanical degradation in archive and library collections. Within heritage science, there is a growing interest in collecting data from the collections in order to validate the results obtained by experimental studies [29]. In the context of environmental management, epidemiology has been suggested as a possible approach to provide evidence for the patterns of decay in collections [30, 31]. The report from the Experts Meeting organized by the Getty Conservation Institute [32] is a good introduction on how epidemiology could be applied to investigate the relationship between objects' mechanical damage and their environment. As the focus of interest is the study of climate-induced damage, epidemiological study designs are discussed taking into account two important limitations: the availability of environmental data, and the ethical issues related to the exposure of objects to potentially damaging conditions.

In the case of wear and tear in archival collections, the focus lies on how epidemiological study designs and data analyses can be applied to obtain quantitative data from large populations. We are particularly interested in the information that could be extracted from surveys. The results of these type of studies on archival and library collections could provide quantitative evidence: (i) to inform surveyors on how to evaluate the data collected during surveys and assessments, reducing the potential interpretational bias when surveyors rely solely on their experience; (ii) to directly support collection management decisions; (iii) to develop mathematical models in which the effect of preservation measures is explored. 


\section{Qualitative approach to failure Reliability: analysis of failure}

In engineering, the term reliability has been introduced to manage the frequency of failure in complex systems. Archival and library collections can be seen as complex systems due to the numerous interconnected components (use, value, material or design etc.). Reliability can be defined as "the probability that an item will perform a required function, under stated conditions" [33]. In this context, failure is the event of "non-conformance to some defined performance criteria" [33]. Therefore, in the context of archival objects failure is when mechanical degradation occurs because when paper is made it is not meant to tear and a book spine is not meant to break. However, it is important to bear in mind that, in reliability, time is always taken into account as a parameter. Therefore, the reliability of an object is "the probability of survival to time $t^{\prime \prime}$ [33].

Reliability distinguishes different failure modes to describe the type of failure [26]. Two major types of failures are identified:'intermittent' and 'extended' failures. Intermittent failures are those which occur only for a short period of time. Looking at wear and tear in archival objects, only extended failures occur as this type of failure continues until some corrective action rectifies them: a tear, understood as a failure, will remain until a conservation treatment takes place. Within extended failures it is possible to distinguish between 'complete' failures, which result in a total loss of function, and 'partial' failures. In the case of an archival object, tears could be considered as 'partial' failure, while a missing piece of paper with text could be considered as 'complete' failure. Failures can also occur suddenly, without any warning signs, or be gradual. Wear and tear is a gradual failure, as a small tear can develop into a large tear and result in a missing piece and loss of text. However, sudden failures are also possible, for example, if a binding is overstressed and breaks.
In reliability, the severity of the failure mode is graded as catastrophic, critical or marginal, terms describing the event of a failure. A study among archival and library users has shown that loss of textual information is seen as critical, whereas other failures regarding the materiality of archival and library objects are graded as marginal [34]. In general, when archival objects are assessed during a survey, the severity of each failure is not individually graded, instead, the survey is used to grade the condition of the object as a whole.

In reliability, according to the IEEE Standard 1413.12002 [35], the causes of a failure are defined as the circumstances during design, manufacture or use which have led to failure (Fig. 1). Another way to divide the causes of failure is by using factors prior to use (design and manufacture) and factors during use (maintenance and usage) [26]. The causes of a failure can be classified as intrinsic (weaknesses in the item, wear-out) or extrinsic (errors, misuse or mishandling during design and production) [36].

\section{Failure causes}

In the previous section, general concepts of reliability were introduced and it was demonstrated that they can be translated to the studies of failure in collections. In this section, the applicability will be scrutinised. We will examine the factors and observations reported by surveys using the failure cause classification system as provided by reliability.

\section{Factors prior to use}

Design In the context of archival and library collections, 'design' can be understood as the physical specifications of an object or, in other words, the material construction of the object: size, type of binding, thickness of paper etc.

The features of an object are closely related to the end-use that the object is meant to fulfil. Bindings are a good example. The purpose of a book will determine the type of binding, resulting for instance in a clear

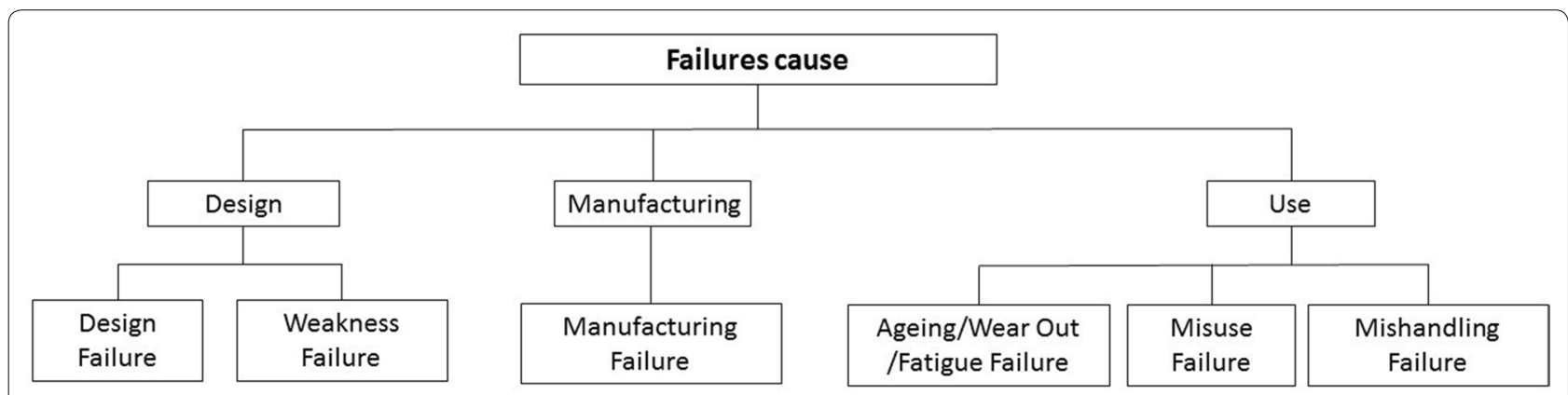

Fig. 1 An example of a classification of failure causes used in reliability engineering, based on Valis and Barlett [36] 
difference between archival and library bindings. Until the 19th century, register books, in contrast to printed books, tended to have a parchment cover rather than a leather one, were oversized and had their own types of binding, such as laced overband or the more modern spring-back binding [37, 38]. Different types of bindings led to different stresses to the materials and the structure on opening [39]. Hence, different types of bindings imply different rates of failure and, if failure occurs, book conservators are well aware that in order to prevent failure after repair, in some cases, the binding design has to be altered.

Economic reasons can also compromise the quality of bindings. In the Yale survey, it was observed that limp bindings were more fragile than rigid covers [18]. In 1906, Cockerell recognized that library bindings have to be cheap due to the large number of books to be bound; however "appearance must be sacrificed to strength and durability, and not, as is too often the case, strength and durability sacrificed to appearance" [40].

The descriptions of physical characteristics of objects provided by condition surveys could be a rich data source to be further analysed to help us to identify which design features (such as the size of the object and types of binding) contribute to the reliability of archival objects.

Manufacture While design refers to the choices that can be made regarding the shape and construction of the objects, manufacture refers to the production of the materials and composite objects.

The history of the production of paper, leather and parchment shares in common the fact that the developments of production processes were always driven by increased demand. Increasing production and reducing the production time negatively affected the end product quality, which plunged dramatically after 1850 [41, 42].

In papermaking, although each step (beating, forming, pressing, drying and calendaring) affects the quality of the end product [43], the choice of raw materials and additives is seen as the major factor affecting paper durability [44]. The importance of the raw materials is illustrated, for instance, by the survey of 19th century paper conducted in Sweden [11]: 63.3\% of the paper graded as being in good condition was made of rags and $6.1 \%$ of chemical pulp. On the other hand, $46.7 \%$ of chemical pulp paper and $13.3 \%$ of rag constituted paper was categorised as poor condition (based on the assessed mechanical degradation and manual fold test).

Similarly to experimental studies, surveys can also inform how raw materials affect the mechanical and chemical properties of paper. Several surveys report a steady decrease in paper stability between 1860 and 1890 $[11,18]$, whereas other surveys fail to detect any increase in stability until 1960 [14]. The surveys conducted more recently $[13,14]$ agree that $\mathrm{pH}$ was alarmingly low $(\mathrm{pH}<5.0)$ until 1980 when neutral sizing was introduced on a large-scale [20]. New concerns have arisen in the last few decades with the introduction of recycled paper, particularly when used as permanent paper in governmental documents $[45,46]$.

Parchment manufacture has remained traditional. In general, parchment is considered as a durable product, composed of $95 \%$ collagen arranged in an oriented network, with pH between 6 and 8 [47]. The most critical stage is when the parchment is drying under tension. However, in the 19th century, lime baths with chemicals such as calcium oxide, calcium carbonate, and sodium sulphide were introduced to accelerate the unhairing of the skins.; the effect was that too much tissue material was removed, resulting in poorer quality parchment [48].

For leather, the tanning process determines the quality of the end-product. In the 19th century, the negative effect of sulphuric acid on leather, known as red rot, became apparent. Studies have shown that the sources of acid are sulphur dioxide present as an air pollutant, as well as the tanning process itself. It has been observed that leather tanned with hydrolysable tannins (such as sumac leaves and chestnuts) degraded less than condensed tannins, such as mimosa bark and gambier leaves [49]. In addition, from the 19th century onwards, the search for faster tanning methods resulted in the use of new techniques, negatively affecting the quality of leather. The traditional, natural dyestuffs combined with alum were replaced with synthetic dyes in combination with other mordants, which required an acidic environment obtained by the addition of sulphuric acid. By the 1870s chrome tanning had been fully adopted and is nowadays still the predominant tanning process [49].

Due to the poorer quality of end-products, manufacturing failures can be anticipated as an important cause of failure for specific groups of objects.

\section{Factors during use}

Maintenance With the introduction of risk assessment, the preservation needs of collections also need to be assessed [15-17]. This includes a list of aspects, from protective folders to environmental control, from integrated pest management to disaster preparedness, and a self-assessment checklist of benchmarks in collection care has been developed [50]. Storage and physical protection practices are particularly well-embedded in preservation policies in archives and libraries. Measures, such as keeping documents unfolded, if possible with objects of similar size, in a folder and/or in a box [51], address the risk of mechanical degradation due to unsuitable storage. However, it has not been quantified yet how effective 
these measures are. It has been observed that boxes do not always prevent mechanical degradation. Losses along edges and corners cam occur due to ill-fitting boxes and permanent deformation of paper can be caused by sagging in boxes that are vertically stored [4].

It is interesting to note that several condition surveys report on folds and tears in chemically stable paper [11, 12]. In such cases, it is possible that such mechanical degradation is evidence of inappropriate storage practices.

Usage Reliability has been defined as the probability of failure, under stated conditions, for a stated period of time [33]. Usage refers not only to mishandling, but also to an intensity of use, more than is reasonable for a certain object. However, what is reasonable for archival objects?

To increase the understanding of the effect of frequency of use on the rate of failure, condition survey results could be plotted against records of use [52]. If condition surveys record whether objects have been in circulation, but not the actual number of times it has been requested in a reading room, such information is not sufficient and conclusions can only partly be drawn for items that have not been requested. An example is the study of paperbacks in an academic library, the Georgia State University's Pullen Library [25]. Because the condition of both circulated and non-circulated books was assessed, the authors were able to conclude that the damage to books which had not circulated was due to poor shelving practices. Interestingly, size was a major factor: taller and thinner volumes suffered more frequent damage than smaller, thicker books. From this example, it follows that the frequency of use could be a key factor in judging the relevance of other failure causes, such as design or storage.

\section{Framework for the analysis of wear and tear}

In the previous section, failure causes have been analysed individually, but they do not need to be seen as separate from each other. An analysis method frequently used to hypothesize root causes is the "fishbone diagram". This is a "cause and effect diagram" where the main bone is the effect and the sub-bones are the causes. This diagram helps to "identify, explore, and display the relationship between an effect and all of its potential causes" [53].

Figure 2 shows a fishbone diagram that could be seen as a first approach to a systematic study of mechanical degradation in archival and library collections. In this diagram the classification of failure causes is based on information that can be collected during a survey.

\section{Failure rate}

During the lifetime of objects, different failure rates or, in other words, different reliability values can be observed. These differences are illustrated by the "bathtub curve" available in [54]. Three types of failure, with different failure rates, can be distinguished: early failures, useful life and wear-out failures. After a decrease in initial failures, the failure rate reaches a steady-state, called "useful life", followed by a sharp rise at the end of the object's lifetime during the wear-out period. This curve illustrates that, during most of the lifetime of an object, if failures

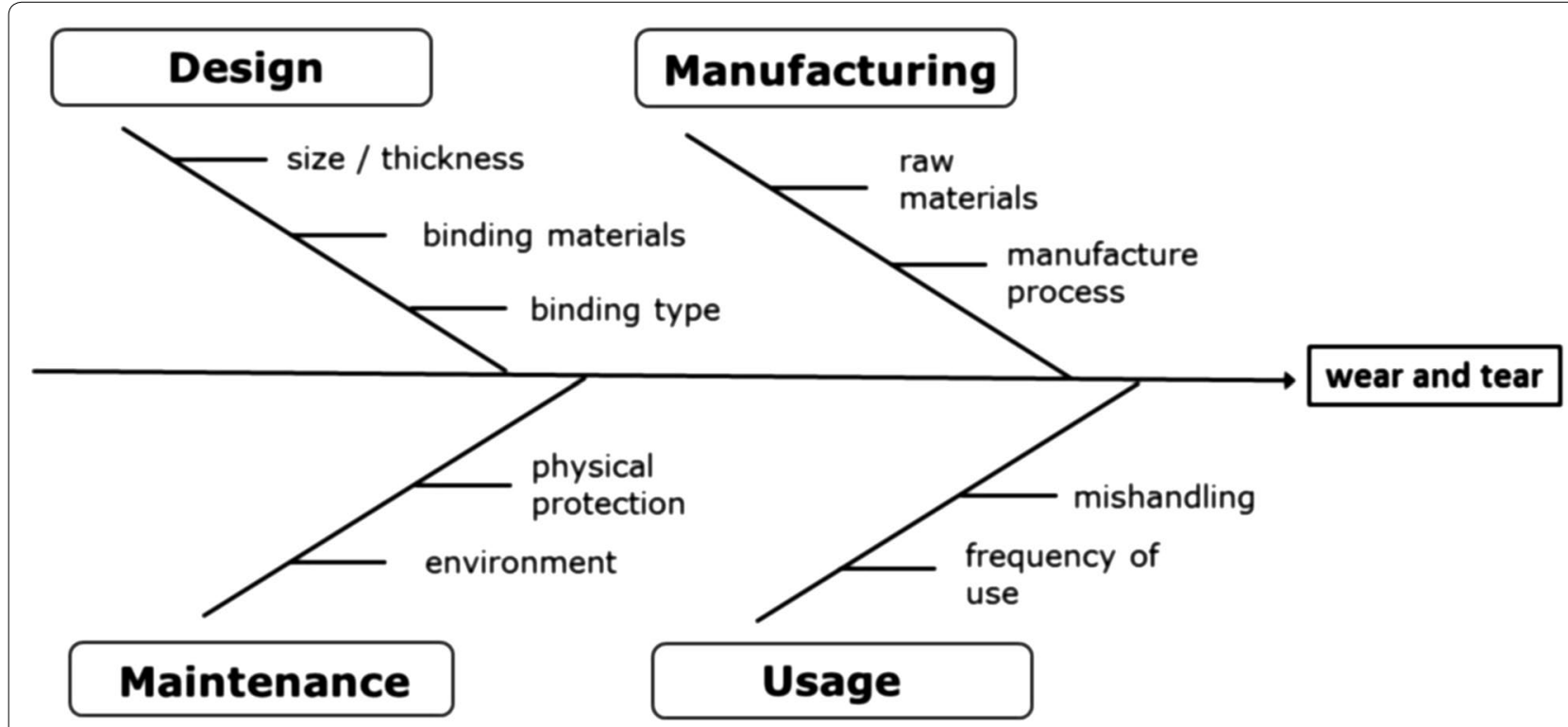

Fig. 2 Fishbone diagram of failure causes related to mechanical degradation in archival and library collections 
occur, these are random, stochastic, and stress-related. However, during wear-out, failures occur notably more frequently, as the object deteriorates due to extensive hydrolysis, oxidation, fatigue etc.

When archival objects become part of a collection, the early failure stage, immediately after the manufacturing process, has already passed. Consequently, failures occur at a constant, low rate during the useful life of the objects, and the probability of failure increases during the wear-out period.

Let us consider the use of a book to illustrate the difference in failure rates. When a book reaches its wear-out period, because the materials, e.g. the sewing, have deteriorated ("aged") or because the book had been intensively used (fatigue), the probability that the object will break increases notably. But if a book is still in its useful life period, perhaps due to good maintenance and/or low use, then the probability of such failure is considerably smaller. However, it can still occur, e.g. due to a design failure.

Different types of paper represent another useful example. Well-maintained and not misused rag paper will easily remain in the useful life period for the foreseeable future. On the contrary, ground-wood paper will rapidly reach the wear-out period due to faster chemical degradation. Failures will therefore occur and accumulate at a significantly higher rate in ground-wood paper than in rag paper, unless ground-wood paper has been maintained in a manner appropriate for this paper type (for instance, storage in a cool environment or deacidification treatment). In the wear-out period, ground-wood paper quickly accumulates mechanical degradation and its absence can only be explained by the absence of use.

It is also important to bear in mind that even poor quality paper has or has had a (short) useful life. Several surveys $[18,55]$ show that some younger paper was still flexible and usable despite its low $\mathrm{pH}$, in contrast to similar but older paper, which was already brittle. This younger paper has probably not reached the critical degree of polymerisation (DP) value when the risk of failure upon use increases, and was therefore still in its useful life period. Recently, an experimental study has introduced actual actions of reading in the experimental design [28]. According to this study, the critical DP was found to be 300 and therefore for papers with a DP higher than 800 , mechanical degradation occurred at a very low rate, independent of DP.

\section{Quantitative approach to failure Survival analysis}

So far we introduced qualitative analysis provided by reliability to study mechanical degradation in collections. A quantitative approach is still required to develop a better understanding of wear and tear, which might be offered by survival analysis [56]. As defined previously, the reliability of an object is "the probability of survival to time $t$ " [33], and the analysis proposed by reliability is based on it being known when the event of failure occurred. In the field of conservation there are a few examples where a survival analysis has been applied. These studies follow a group of objects through time, and repeated assessments are carried out to examine whether failure has occurred.

In the study by Keene [57], 588 excavated iron objects where examined 2, 5 and 8 years after treatment in order to find evidence of which treatment and storage conditions contributed most to stabilization of their condition. Because the objects were surveyed at different points in time the authors were able to build life tables, which calculate the probability that an object will survive a certain period of time after treatment or during storage. In this study, an object is considered to 'survive' if its condition remains stable and to 'fail' if graded as unstable (i.e. the slightest sign of fresh corrosion or lifting of mineral layers).

Whereas life tables investigate the probability of an event (failure) occurring during a certain time interval, the probability of transition between condition states can be calculated using Markov chains. Markov models are used when a deterioration process is random, e.g. in the study of mechanical damage to masonry in aggressive environments $[58,59]$.

Markov models have also been applied to quantify the dynamics of degradation of printed materials in libraries [23]. A particularly interesting aspect of this method is that condition survey data is used to build a Markov chain. The condition of paper and bindings of 144 books was graded according to the observed damage, using the Stanford method [10]. In addition, paper folding tests and $\mathrm{pH}$ measurements were conducted. The books were assessed at the beginning and at the end of a 15 year period. Based on these data, the transition probabilities between condition states were calculated.

By using Markov chains, the author assumes that failure (understood as transition between pre-defined states) is a stochastic event which occurs randomly. However, as argued in the previous sections, in the case of archive and library collections, we might still be interested in identifying the factors that have an effect on the reliability of certain group of objects, and at which point they reach the wear-out phase, when the probability of failure increases. When the focus is not just to study failure as a function of time, but also as a function of specific factors, then proportional hazard models, also called multivariate life tables, can be applied [56]. In these models a baseline hazard function is calculated, describing the probability that a failure occurs within a certain time interval 
(risk), and the proportionate increase or reduction in risk, associated with a set of characteristics [60]. Time to failure remains a key element in this type of studies, and therefore the individuals need to be followed during a certain period of time, usually several decades. Although this long study period is not unusual in medical studies, in the heritage field studies that last more than 15 years are very exceptional and only few examples can be found where the study period lasted for several decades. One example is the experimental study conducted in the period 1930-1980 to determine the effects of environmental conditions on the chemical degradation of leather bindings [49]. For this study two duplicate sets of books were bound, stored in two different environments, in the British Library and in the National Library of Wales in Aberystwyth, and assessed during a period of 50 years. The results clearly showed the negative effect of London's acidic pollution, as well the higher quality of leathers produced using hydrolysable tannins.

For paper-based collections, a long study period will also be required as changes in objects are difficult to measure; the accuracy and precision of e.g. $\mathrm{pH}$ measurement is not sufficient, and degradation processes (usually) occur at a slow rate.

\section{Epidemiology}

This discipline has been described as "the science and practice that describes and explains disease patterns in populations" [61]. In an epidemiological study, individuals are (randomly) selected from a (large) population, not only to describe the occurrence of a disease but also to infer how the characteristics of individuals may have an effect on the event of interest. Epidemiology seeks "to understand whether and how differences in individuals might explain patterns of disease distribution across a population" [62].

Epidemiological studies are thus conducted on populations. The concept of population used for heritage collections, in particularly archival and library collections, was introduced during the Collections Demography project [63]. Populations are composed of groups of individuals (collections), which will age differently depending on the preservation measures taken.

Most epidemiological studies involve the comparison of groups of individuals sharing certain characteristics [61]. In order to compare groups, a set of variables is selected for assessment during the observational study. Two main types of variables can be distinguished: outcome and exposure variables. The outcome variable is degradation or damage that we are seeking to understand, and exposure variables are the factors that may influence the extent or occurrence of the outcome variable [64]. In the case of archive collections, this approach would analyse the relationship between mechanical failure (the outcome variable), and factors related to the design, manufacture, maintenance or use, that might affect such failure (exposure variables).

Similarly to the survival analysis discussed in the previous section, some epidemiological studies are designed to follow individuals over a certain period of time, also called longitudinal studies. Because it is known when the event of interest happened, this type of study provides information on the rate of degradation (survival rate) and risk ratio.

\section{Experimental studies}

Longitudinal studies can be designed as experimental as well as an observational study. In experimental studies, sampling is conducted on a population, but the researcher intervenes, for instance, to choose the individuals and/or to vary some characteristics or exposure of the individuals. An example of an experimental study using a non-randomized trial design, is given by Pastorelli et al. [65]. Over a 2 year period, 18 polymers samples, selected from two historic collections, were exposed to different environmental conditions at 11 sites across Europe and North Africa. Multivariate data analysis, such as principal components analysis (PCA) was conducted to find associations between the outcome variable (colour change) and the exposure variables (different environmental parameters).

However, when dealing with large populations, a more strong epidemiological study design is randomized controlled trials. Individuals are randomly selected from a population and then a group of individuals is exposed to a certain condition. This design is considered one of the most robust studies in epidemiology [66]. In medical studies, randomized controlled trials are usually used to compare the effect of treatments.

\section{Observational studies}

In contrast to the experimental study designs, in observational studies "the researcher has no control over what subjects are in what groups and just observes and analyses the existing situation" [61]. Observational studies can be subdivided in three groups: "the cross-sectional study, which takes a snapshot in time, the cohort study, which follows a population through time from cause to effect, and the case-control study, which looks backwards in time from effect to cause" [62].

Cohort studies Cohort studies are similar to the randomized controlled trials, but as the research only observes the changes experimented by the individuals, these type of studies are a good approach to find associates between outcome and a (broad) set of exposure variables. In pro- 
spective cohort studies the study starts before individuals have developed any of the outcomes of interest. In the case of existing data, already collected for other uses, a cohort can be "followed-up" retrospectively [67]. Retrospective cohort studies follow the same methodology as a prospective cohort study, which means that the data (outcomes and exposures variables) have been collected over time, and not at a single point in the time, as in case-control studies and cross-sectional studies.

Case-control study In case-control studies, the cases are selected because they have already developed a symptom and then compared with the controls, without such symptoms. Cases and control cases are taken from the same population. The difficulty of this study design lies in finding cases and controls with similar characteristics but differing in their exposure history. However, control-case studies have two major advantages compared to cohort studies: the time frame (case-control studies deal with existing cases and there is no need for decades of followup), and the smaller sample size required [68].

In the case of archival and library collections, the cases would be those showing mechanical degradation and the controls those which have developed no tears or missing pieces. Differences in exposure variables, for example, frequency of use or type of protection enclosure, could be then explored between controls and cases. In order to select cases and controls that just differ in a limited number of exposures, this type of studies should be conducted only on a (homogenous) collection within the archive or library.

Cross-sectional studies The third type of observational study design used by epidemiology are surveys, a crosssectional study carried out at a single point in time. In this case, multiple exposures and outcomes are assessed simultaneously. Cross-sectional studies, similar to other observational studies in epidemiology, may be purely descriptive. A good example of a descriptive cross-sectional study is a (condition) survey carried out in a heritage collection. It would be designed to report the prevalence of outcomes of interest, as well as the prevalence of an outcome among a certain group of individuals.

However, cross-sectional studies can also be analytical. Such studies are used to explore associations between the exposure variables and the event of interest (e.g. outcome variable). Cross-sectional studies can compare disease prevalence between exposure groups, similar to cohort studies, as well as the level of exposure between two groups, as in case-control studies. However, as they cannot estimate the absolute risk, the causality, or the survival rate for a particular event [68], crosssectional studies provide the lowest level of evidence in the research hierarchy [66]. Cross-sectional studies only explore associations, and generate hypotheses that need to be further explored using other observational or experimental study designs.

To analyse associations between variables in crosssectional studies, exploratory statistical analysis is used. A good example of this type of analysis is given by Sully et al. [22]. 660 archaeological leather artefacts treated by glycerol (propane-1,2,3-triol) impregnation were surveyed. The actual size of the sample was determined by the variability of the collection. The collected data consisted of administrative information, object description and condition of the object, grading friability and flexibility of the materials. Two-sample $t$-tests were conducted to identify whether the mean difference of the condition score ore the different percentages of glycerol used was statistically significant between two sites. The results showed that the object period and the concentration of glycerol used were the variables that significantly affect the condition of leather in long-term storage.

To explore correlations between more than two variables, multivariate analysis can be conducted, such as PCA and multiple regression. An example of this approach is given by Možir et al. [69]. In their study on parchment degradation, the data collected from a reference collection of historic parchment (100 samples) was analysed statistically using principal component analysis to find correlations between the shrinkage temperature, indicator of parchment degradation (outcome variable), and a number of exposure variables (such as $\mathrm{pH}$, lipid content or age of the documents).

\section{Conclusion}

We showed that the qualitative approach provided by reliability can be easily applied to the study of mechanical degradation of heritage objects. General concepts, such as failure, failure modus and failure rate, provide insights into mechanical degradation, if wear and tear is understood as failure. The proposed division of causes of failure, to factors prior to use (design and manufacture) and factors during use (maintenance and usage), emerged as particularly useful to systematically analyse the possible factors involved in mechanical degradation. When the information provided by surveys and experimental studies is put into this framework, then it becomes clear that the effect of manufacture and maintenance have received significantly more attention, whereas design and usage have been understated and are not well understood.

We also reviewed the few quantitative studies that have been conducted using survival analysis or epidemiological approaches to study failure in heritage collections. The most robust studies are those were 
the sampled individuals are followed during a certain period of time, usually several decades, and past exposure is compared between those who have developed the symptoms of degradation and those who have not. The drawbacks of this type of studies are the long time frames and the large sample sized usually required.

Therefore, a first approach to study wear and tear could be to conduct cross-sectional studies, surveys, which are also a type of design within epidemiological observational studies. These studies are conducted at one single point and are used as hypothesis generator. In these studies, the event of interest (e.g. mechanical degradation) might be the outcome variable and the factors that might have an effect on the outcome (e.g. design, manufacture, maintenance and use), the exposure variables. If data is purposely collected surveys can provide more than just descriptive information (prevalence of certain damage). The results of statistical analysis, e.g. $t$-test for mean difference between comparison groups and multivariate analysis, such as PCA and multiple regression, could then provide the evidence needed to answer the question how mechanical degradation occurs. In Part II of this study we will look at how these concepts come together in a case study.

\section{Abbreviations}

IEEE: Institute of Electrical and Electronics Engineers; DP: degree of polymerisation; PCA: principal components analysis.

\section{Authors' contributions}

$C D, J G$ and MS developed the concept of this work. CD wrote the manuscript, MS reviewed the whole text and made comments and suggestions to improve it. MS edited parts of the manuscript. All authors read and approved the final manuscript.

\section{Author details}

${ }^{1}$ Institute for Sustainable Heritage, University College London, London, UK.

${ }^{2}$ Amsterdam City Archives, Amsterdam, The Netherlands.

\section{Acknowledgements}

The authors gratefully acknowledge the financial support of Prins Bernhard Cultuurfonds (NL) and Metamorfoze, the Netherlands' national programme for the preservation of paper heritage. We would also like to thank the EPSRC Centre for Doctoral Training in Science and Engineering in Arts, Heritage and Archaeology (SEAHA).

\section{Competing interests}

The authors declare that they have no competing interests.

\section{Availability of data and materials}

Not applicable.

\section{Funding}

UK Engineering and Physical Sciences Research Council grant Centre for Doctoral Training Science and Engineering in Art, Heritage and Archaeology; Prins Bernhard Cultuurfonds (NL) and Metamorfoze, the Netherlands' national. programme for the preservation of paper heritage.

\section{Publisher's Note}

Springer Nature remains neutral with regard to jurisdictional claims in published maps and institutional affiliations.
Received: 9 October 2018 Accepted: 14 February 2019

Published online: 01 March 2019

\section{References}

1. Bell N. The Oxford preservation survey. A method for surveying archives. Pap Conserv. 1993;17(1):53-5.

2. Albrecht-Kunszeri G, De Bruin G. A model for damage survey and international cooperation. In: La conservation à l'ère du numérique: actes des quatrièmes journées internationales d'études de l'ARSAG, Paris, 27-30 May 2002. 2002. p.162-72.

3. British Library Board. A programme to address the strategic challenges for preservation and conservation vision and strategy - purpose statement. London: British Library; 2009.

4. Bülow AE. Collection management using preservation risk assessment. J Inst Conserv. 2010;33(1):65-78.

5. Strlič M, Kolar J, editors. Ageing and stabilisation of paper. Ljubljana: National and University Library; 2005.

6. Pickwoad N. The condition survey of the manuscripts in the monastery of Saint Catherine on Mount Sinai. Pap Conserv. 2004;28(1):33-61.

7. Waller R. Cultural property risk analysis model: development and application to preventive conservation at the Canadian Museum of Nature. Goteborg: Acta; 2003

8. National Library of Australia. Preservation needs assessments. http:// www.nla.gov.au/chg/preservation-needs-assessments. Accessed 14 Nov 2014.

9. Taylor J. An integrated approach to risk assessments and condition surveys. J Am Inst Conserv. 2005;44(2):127-41.

10. Buchanan S, Coleman S. Deterioration survey of the Stanford University Libraries Green Library Stack collection. In: Darling PW, editor. Preservation planning program: resource notebook. Washington, D.C.: Association of Research Libraries, Office of Management Studies; 1982. p. 159-91.

11. Palm J, Cullhed P. Deteriorating paper in Sweden. FoU-project för paperskonservering. 662 Report no.3. Stockholm; 1988.

12. Mijland H, Ector F, Van Der Hoeven K. The Eindhoven variant: a method to survey the deterioration of archival collections. Restaurator. 1991;12(3):163-82.

13. Konsa K. Condition survey for the Estonian national preservation policy. Restaurator. 2007;28(4):239-55.

14. Sobucki W. Survey of the preservation status of the 19th and 20th century collections at the National Library in Warsaw. Restaurator. 2003;24(3):189-201.

15. Eden P, Dungworth N, Bell N, Matthews G. A model for assessing preservation needs in libraries. Boston Spa: British Library Research and Innovation Centre; 1998.

16. Van der Reyden D, Tennison H, Wen Tsai F. Publish, then perish: reclamation of a collection of scientific illustrations. Restaurator. 1996;17(2):104-15.

17. Walker G. Assessing preservation needs. Libr Resour Tech Serv. 1989;33(4):414-9.

18. Walker RG, Greenfield J, Fox J, Simonoff JS. The Yale Survey: a large-scale study of book deterioration in the Yale University Library. Coll Res Libr. 1985;46(2):111-32.

19. Bond R, Decarlo M, Henes E, Snyder E. Preservation study at the Syracuse University Libraries. Coll Res Libr. 1987;48(2):132-47.

20. Baird BJ, Krentz J, Schaffner B. Findings from the condition surveys conducted by the University of Kansas Libraries. Coll Res Libr. 1997;58(2):115-26.

21. Teper JH, Erekson SM. The condition of our "Hidden" rare book collections. Libr Resour Tech Serv. 2006;50(4):51-65.

22. Sully D, Suenson-Taylor K. A condition survey of glycerol treated freeze-dried leather in the long-term storage. In: Roy A, Smith P, editors. Archaeological conservation and its consequence. Preprints of the Contributions to the Copenhagen Congress. 1996. p. 177-81.

23. Konsa K. Conservation strategies. A deterioration model of printed materials. Pap Restaurierung. 2008;9(2):29-33.

24. Peach C, Foster J. Knowing the need library and archive collections. London: British Library Preservation Advisory Centre; 2013.

25. Presley RL, Landram C. The life expectancy of paperback books in academic libraries. Tech Serv Q. 1990;7(4):1-9. 
26. Blischke WR, Prabhakar MDN. Reliability: modeling, prediction, and optimization. New York: Wiley; 2000.

27. Rausand M, Hoyland A. System reliability theory. 2nd ed. New Jersey: Wiley; 2004.

28. Strlič M, Grossi CM, Dillon C, Bell N, Fouseki K, Brimblecombe P, et al. Damage function for historic paper. Part II: wear and tear. Herit Sci. 2015;3(1):36.

29. Van Duin P. Climate effects on museum objects: the need for monitoring and analysis. GCI Newsl. 2014;29(2):13-5.

30. Managing Collection Environments Initiative. Epidemiology. 2015. http:// www.getty.edu/conservation/our_projects/education/managing/epide miology.html. Accessed 24 June 2017.

31. Thickett D, Odlyha M. Epidemiology—-the missing link? In: 2nd international SEAHA conference book of abstracts. 2016. p. 12.

32. Druzik J, Boersma F, editors. Epidemiology. Basic ideas applied to museum collections. Los Angeles: Getty Conservation Institute; 2017.

33. Smith DDJ. Reliability, maintainability and risk. Practical methods for engineers. 6th ed. Oxford: Butterworth-Heinemann; 2001.

34. Strlič M, Grossi CM, Dillon C, Bell N, Fouseki K, Brimblecombe P, et al. Damage function for historic paper. Part l: fitness for use. Herit Sci. 2015;3:33.

35. Institute of Electrical and Electronics Engineers (IEEE). IEEE Standard 1413.1-2002. In: IEEE guide for selecting and using reliability predictions based on IEEE1413. New York: Institute of Electrical and Electronics Engineers; 2003

36. Valis D, Bartlett LM. The failure phenomenon: a critique. Int J Perform Eng. 2010;6(2):181-90.

37. Meeuws W. Boekbanden in het Stadsarchief Amsterdam [Bindings in the Amsterdam City Archives]. In: Bijzondere archiefbanden: constructie en gebruik. Minisymposium, 12 November 2012. Belgisch-Nederlands Boekbandengenootschap; 2012.

38. Peláez Alcántara S. Course review 'Stationery bindings: history, development and treatment'. 2013. http://thebookandpapergathering. org/2013/08/05/course-review-stationerybindings-history-developmen t-and-treatment-with-bibliography/. Accessed 24 Nov 2014.

39. Conroy T. The movement of the book spine. B \& Pap Gr Annul. 1987:6:1-30.

40. Cockerell D. Bookbinding, and the care of books. A handbook for amateurs bookbinders and librarians. New York: D. Appleton and Company; 1906

41. Clapp VW. The story of permanent/durable book-paper, 1115-1970 Restaurator. 1972;1(s3):1-51. https://doi.org/10.1515/rest.1972.1.s3.1

42. Hunter D. Papermaking. The history and technique of an ancient craft. New York: Dover Publictions; 1987.

43. Rance $\mathrm{H}$, editor. Handbook of paper science: the raw materials and processing of papermaking, Vol. 1. Amsterdam: Elsevier Science Ltd; 1980.

44. Gurnagul N, Howard RC, Zou X, Uesaka T, Page DH. The mechanical permanence of paper: a literature review. J Pulp Pap Sci. 1993;19:160-6.

45. Letnar MC, Vodopivec J. Influence of paper raw materials and technological conditions of paper manufacture on paper ageing. Restaurator. 1997;18:73-91.

46. France F, Kullman M. Recycled paper research at the library of congress. Int Preserv News. 2009;48(August):10-6.
47. Kennedy CJ, Wess TJ. The structure of collagen within parchment-a review. Restaurator. 2003;24(2):61-80.

48. Hallabeek PB, editor. Revised guidelines for the conservation of leather and parchment bookbindings. Amsterdam: ICN; 1997.

49. Leather Thomson R. In: May E, Jones M, editors. Conservation science. Cambridge: RSC Publishing; 2006. p. 92-120.

50. Dawson A, editor. Benchmarks in collection care for museums archives and libraries. MLA; 2011.

51. Ogden S. Storage methods and handling practices. In:Technical Leaflet, Section 4, Leaflet 1. Northeast Document Conservation Center; 1999.

52. Ashley-Smith J. Risk assessment for object conservation. Boston: Butterworth-Heinemann; 1999.

53. Kapur KC, Pecht M. Reliability engineering. New York: Wiley; 2014.

54. Strlič M, Thickett D, Taylor J, Cassar M. Damage functions in heritage science. Stud Conserv. 2013;58:80-7.

55. Barrow WJ. Deterioration of book stock. Causes and remedies. Richmond: The Virginia State Library; 1959.

56. Retherford R, Choe M. Statistical models for causal analysis. New York: Wiley; 1993.

57. Keene S. Real-time survival for treatments of archaeological iron. In: Scott DA, Pondany J, Considine BB, editors. Ancient \& historic metals: conservation and scientific research proceedings of a symposium organized by the J Paul Getty Museum and the Getty Conservation Institute, November 1991. Marina del Rey: Getty Publications; 1994. p. 249-64.

58. Garavaglia E, Anzani A, Luigia A, Ae B, Cardani G. Fragility curve probabilistic model applied to durability and long term mechanical damage of masonry. Mater Struct. 2008;41(4):733-49.

59. Garavaglia E, Basso N, Sgambi L. The Markovian approach for probabilistic life cycle assessment of existing structures. Appl Math. 2012;3:2080-8.

60. Rodriguez G. Lecture notes on generalized linear models. 2007. http:// data.princeton.edu/wws509/notes/. Accessed 13 July 2018.

61. Bhopal RS. Concepts of epidemiology. Integrating the ideas, theories, principles, and methods of epidemiology. 3rd ed. Oxford: Oxford University Press; 2016.

62. Jewell N. Statistics for epidemiology. London: Chapman \& Hall; 2003.

63. Strlič M. Collections demography. Part 1: on dynamic evolution of populations of objects. 2013. https://www.youtube.com/watch?v=BaObm 6D0Sn8. Accessed 18 June 2018.

64. Kirkwood BR, Sterne JAC. Essential medical statistics. 2nd ed. Oxford: Blackwell Science; 2003

65. Pastorelli G, Cucci C, Garcia O, Piantanida G, Elnaggar A, Cassar M, et al. Environmentally induced colour change during natural degradation of selected polymers. Polym Degrad Stab. 2014;107:198-209.

66. Jin J, And W, Attia J. Study designs in epidemiology and levels of evidence. Am J Ophthalmol. 2010;149(3):367-70.

67. Mann CJ. Observational research methods. Research design II: cohort, cross sectional, and case-control studies. Emerg Med J. 2003;20:54-60.

68. Daly LE, Bourke GJ. Statistical analysis, interpretation and uses of medical statistics. 5th ed. Oxford: Blackwell Science Ltd; 2000.

69. Možir A, Cigic IK, Marin M, Strlič M. Material properties of historic parchment: a reference collection survey. Stud Conserv. 2014:59(3):136-49.

\section{Submit your manuscript to a SpringerOpen ${ }^{\odot}$ journal and benefit from:}

- Convenient online submission

- Rigorous peer review

- Open access: articles freely available online

- High visibility within the field

- Retaining the copyright to your article

Submit your next manuscript at $\boldsymbol{\nabla}$ springeropen.com 